\title{
Da Facultade de Economía e Empresa (UDC) á práctica profesional: 0 TFG baseado en ABPy como ponte académica-formativa "experiencial"
}

\author{
De Llano Paz, Fernando; Martínez Fernández, Paulino
}

Departamento de Empresa, Facultade de Economía e Empresa, Universidade da Coruña.

\section{RESUMO}

A proposta dun Traballo de Fin de Grao é unha responsabilidade para o docente que o oferta, por canto neste deben integrarse e desenvolverse os contidos formativos do Grao, xunto coas competencias e habilidades adquiridas. Sen embargo a responsabilidade é compartida, xa que é a/o estudante quen debe demostrar a súa capacitación en competencias propias do saber das disciplinas estudadas.

Neste contexto os autores propoñen o emprego da metodoloxía da "Aprendizaxe Baseada en Proxectos (ABPy)" como a máis acaída para desenvolver o TFG titulado Análise de produtos bancarios dende unha perspectiva financeira e ofertado na Facultade de Economía e Empresa (UDC) para un grupo máximo de 4 estudantes no curso 2017-18. 0 problema dinamizador é propio do mundo real e da práctica profesional dun egresado do Grao en ADE/Economía: analizar 0 impacto que ten no custo para 0 cliente dunha entidade financeira os cambios nas variables que afectan ao mesmo dentro do contexto da transparencia das operacións e protección da clientela.

Os resultados acadados son moi satisfactorios tanto para 0 alumnado como para os docentes. A metodoloxía é a acaída para este TFG, co que se ofrece unha entrada titorizada na práctica profesional financeira.

PALABRAS CLAVE: ABPy; TFG; Grao en Empresariais; Circular 8/1990 Banco de España; Circular 5/2012 Banco de España. 


\section{CITA RECOMENDADA:}

De Llano Paz, F.; Martínez Fernández, P. (2019): Da Facultade de Economía e Empresa (UDC) á práctica profesional: o TFG baseado en ABP y como ponte académica-formativa "experiencial". En De la Torre Fernández, E. (ed.) (2019). Contextos universitarios transformadores: construíndo espazos de aprendizaxe. III Xornadas de Innovación Docente. Cufie. Universidade da Coruña. A Coruña (pág. 199-212).

DOl capítulo: https://doi.org/10.17979/spudc.9788497497121.199

DOl libro: https://doi.org/10.17979/spudc.9788497497121

\section{ABSTRACT}

The proposal of a Final Degree Project is a responsibility for the teacher, because in this Project offered the Degree's training content must be integrated and developed, together with the skills and abilities acquired. Nevertheless the responsibility is shared, since it is the student who must demonstrate their qualification in own competitions of the knowledge of subjects studied.

In this context, the authors propose the use of the methodology of "Project Based Learning (ABPy)" as the most appropriate to develop the TFG entitled Analysis of banking products from a financial perspective and offered at the Faculty of Economics and Business (UDC) for a maximum of 4 students group during 2017-18 academic year. The dynamizing problem is based on one of the profesional current practice of a graduate of the Degree in ADE / Economics: analyzing the impact of different changes managed by a financial institution on the variables that affect the cost for the client within the context of transparency of operations and customer protection

The results achieved are very satisfactory both for students and for teachers. The methodology is appropriate for this TFG, which offers a tutored entry in professional financial practice.

KEY WORDS: PBL; FDP; Business Bachelor; Circular 8/1990 Banco de España; Circular 5/2012 Banco de España. 


\section{INTRODUCCIÓN}

A UDC sinala que o perfil dun futuro alumnado do Grao en Ciencias Empresariais impartido na Facultade de Economía e Empresa é aquel que ten certa "inquietude e interese polo mundo da xestión das organizacións, nomeadamente das empresas, con orientación á toma da decisión, con gran capacidade de relación de conceptos, técnicas e situacións".

Os estudantes do grao en Empresariais reciben formación sobre como aplicar os conceptos propios da organización e as técnicas que se empregan na empresa nas súas diferentes áreas funcionais. Así mesmo, traballan para comprender as distintas relacións que poidan existir entre as sinaladas áreas funcionais e cos obxectivos e a misión e visión da empresa. Preténdese, por tanto, formar a profesionais do eido empresarial con capacidade e recursos á hora da toma de decisións, con habilidades na asunción de tarefas directivas e que sexan quen de analizar e resolver os problemas que poidan xurdir dentro da organización. É especialmente relevante a formación académica e profesional en materia de xestión contable e de sistemas de información empresarial.

A práctica profesional dos egresados en Ciencias Empresariais está relacionada coa asunción de responsabilidades laborais ben en postos de mando intermedio -xefe de equipo- ou ben de alta dirección. Ao tratarse dunha formación académica polivalente, complementada coas prácticas en empresa, poden asumir calquera tarefa empresarial como pode ser a de coordinar, dirixir, controlar, organizar e/ou planificar as actuacións a levar a cabo e a política xeral de calquera empresa. Deste xeito, o seu traballo pode estar ligado a calquera das áreas da empresa como a de contabilidade, comercialización, vendas, estratexia, loxística, sistemas de información, recursos humanos ou dirección, entre outras. Segundo o sinalado, os perfís profesionais dos graduados en Ciencias Empresariais con moi variados e entre eles atópanse os de alta dirección, analista empresarial, consultaría, auditoría, emprego por conta propia, analista de mercados, directivo nivel intermedio, persoal da administración pública ou persoal docente. 
A contorna de traballo está caracterizada pola crecente globalización económica que obriga ás empresas a emprender procesos de internacionalización. En todo caso, o contexto económico e empresarial vai estar condicionado por certa inestabilidade, complexidade e dinamismo.

Dentro deste contexto, sitúase a proposta do Traballo de Fin de Grao (en diante, TFG) cun peso de 12 créditos ECTS dentro dos estudos do Grao en Empresariais. Trátase dunha responsabilidade para 0 docente que 0 oferta, por canto neste deben integrarse $\mathrm{e}$ desenvolverse os contidos formativos do Grao, xunto coas competencias e habilidades adquiridas (Rullan et al., 2011). Sen embargo, a responsabilidade é compartida, xa que é a/o estudante quen debe demostrar a súa capacitación en competencias propias do saber das disciplinas estudadas (Rekalde, 2011).

Os autores propoñen 0 emprego da metodoloxía da "Aprendizaxe Baseada en Proxectos (ABPy)" como a máis acaída para desenvolver o TFG titulado Análise de produtos bancarios dende unha perspectiva financeira e ofertado na Facultade de Economía e Empresa (UDC) para un grupo máximo de 4 estudantes no curso 2017-18.

A continuación, desenvolveranse os elementos máis relevantes desta proposta didáctica. Así, no punto 2, describirase os elementos máis relevantes sobre a experiencia; no punto 3 , exporanse os resultados; e no punto 4, proporanse as conclusións.

\section{DESCRICIÓN DA EXPERIENCIA}

\section{1.- CONTEXTUALIZACIÓN DO TFG NOS ESTUDOS DO GRAO EN CIENCIAS EMPRESARIAIS}

0 Grao en Ciencias Empresariais que se imparte na Facultade de Economía e Empresa da UDC presenta un plan de estudos que abrangue catro anos académicos, divididos en dous cuadrimestres cada un, nos que se cursa un total de 38 materias, ademais da realización dun Traballo de Fin de Grao para completar unha formación total de 240 créditos ECTS.

0 plan de estudos está composto por unha oferta total de 41 materias distribuídas ao longo dos catro cursos académicos de duración do Grao (Táboa 1), ademais da posibilidade de facer prácticas externas de carácter optativo e por un total de 6 créditos ECTS, e da realización 
obrigatoria do Traballo de Fin de Grao cun peso de 12 créditos ECTS. En total, o plan de estudos contén 10 materias de formación básica entre $1^{\circ}$ e $2^{\circ}$ curso (60 créditos ECTS), 22 materias de carácter obrigatorio (132 créditos ECTS) nos catro cursos ao que se lle une 0 Traballo de Fin de Grao con outros 12 créditos ECTS. É por isto que os alumnos deben escoller 6 materias de carácter optativo de 6 créditos ECTS cada unha (36 créditos optativos en total) para completar unha formación total de 240 créditos ECTS.

\begin{tabular}{|c|c|c|c|c|}
\hline \multicolumn{5}{|c|}{ PRIMEIRO CURSO } \\
\hline CÓDIGO & NOME & PERÍODO & TIPO & CRÉDITOS \\
\hline $650 G 01003$ & Economía da Empresa: Función Organizativa & $1^{0}$ cuadrimestre & Formación básica & 6 \\
\hline $650 G 01005$ & Historia da Empresa & $1^{0}$ cuadrimestre & Formación básica & 6 \\
\hline $650 \mathrm{G} 01001$ & Introdución ao Dereito & $1^{0}$ cuadrimestre & Formación básica & 6 \\
\hline 650G01004 & Matemáticas I & $1^{0}$ cuadrimestre & Formación básica & 6 \\
\hline $650 \mathrm{G} 01002$ & Principios de Microeconomía & $1^{0}$ cuadrimestre & Formación básica & 6 \\
\hline 650G01006 & Dereito Mercantil & $2^{0}$ cuadrimestre & Obrigatoria & 6 \\
\hline 650G01008 & Economía da Empresa: función financeira & $2^{0}$ cuadrimestre & Formación básica & 6 \\
\hline $650 \mathrm{G} 01007$ & Economía Mundial e Española & $2^{0}$ cuadrimestre & Obrigatoria & 6 \\
\hline $650 \mathrm{G} 01009$ & Estatística I & $2^{0}$ cuadrimestre & Formación básica & 6 \\
\hline $650 \mathrm{G} 01010$ & Matemáticas II & $2^{0}$ cuadrimestre & Formación básica & 6 \\
\hline \multicolumn{5}{|c|}{ SEGUNDO CURSO } \\
\hline CÓDIGO & NOME & PERÍODO & TIPO & CRÉDITOS \\
\hline $650 G 01014$ & Análise das Operacións Financeiras & $1^{0}$ cuadrimestre & Obrigatoria & 6 \\
\hline $650 \mathrm{G} 01013$ & Contabilidade Financeira I & $1^{0}$ cuadrimestre & Obrigatoria & 6 \\
\hline $650 \mathrm{G} 01012$ & Introdución á Socioloxía Industrial e da Empresa & $1^{0}$ cuadrimestre & Formación básica & 6 \\
\hline $650 \mathrm{G} 01015$ & Macroeconomía & $1^{0}$ cuadrimestre & Formación básica & 6 \\
\hline $650 \mathrm{G} 01011$ & Réxime Fiscal da Empresa I & $1^{0}$ cuadrimestre & Obrigatoria & 6 \\
\hline $650 \mathrm{G} 01017$ & Contabilidade Financeira II & $2^{0}$ cuadrimestre & Obrigatoria & 6 \\
\hline $650 \mathrm{G} 01019$ & Dirección Financeira I & $2^{0}$ cuadrimestre & Obrigatoria & 6 \\
\hline $650 \mathrm{G} 01018$ & Estatística II & $2^{0}$ cuadrimestre & Obrigatoria & 6 \\
\hline $650 \mathrm{G} 01020$ & Informática Aplicada á Empresa & $2^{0}$ cuadrimestre & Obrigatoria & 6 \\
\hline $650 \mathrm{G} 01016$ & Organización de Empresas & $2^{0}$ cuadrimestre & Obrigatoria & 6 \\
\hline \multicolumn{5}{|c|}{ TERCEIRO CURSO } \\
\hline CÓDIGO & NOME & PERÍODO & TIPO & CRÉDITOS \\
\hline 650G01022 & Bases de Datos para a Empresa & $1^{0}$ cuadrimestre & Obrigatoria & 6 \\
\hline $650 \mathrm{G} 01023$ & Contabilidade de Custos & $1^{0}$ cuadrimestre & Obrigatoria & 6 \\
\hline $650 \mathrm{G} 01025$ & Dirección Financeira II & $1^{0}$ cuadrimestre & Obrigatoria & 6 \\
\hline $650 \mathrm{G} 01024$ & Introdución á Econometría & $1^{0}$ cuadrimestre & Obrigatoria & 6 \\
\hline 650G01021 & Réxime Fiscal da Empresa II & $1^{0}$ cuadrimestre & Obrigatoria & 6 \\
\hline $650 \mathrm{G} 01030$ & Contabilidade de Sociedades & $2^{\circ}$ cuadrimestre & Obrigatoria & 6 \\
\hline 650G01026 & Dereito do Traballo e da Seguridade Social & $2^{0}$ cuadrimestre & Obrigatoria & 6 \\
\hline
\end{tabular}




\begin{tabular}{|c|c|c|c|c|}
\hline $650 G 01029$ & Inglés Empresarial & $2^{0}$ cuadrimestre & Obrigatoria & 6 \\
\hline $650 G 01027$ & Réxime Fiscal da Empresa III & $2^{0}$ cuadrimestre & Obrigatoria & 6 \\
\hline $650 G 01028$ & Sistema Financeiro Español & $2^{0}$ cuadrimestre & Obrigatoria & 6 \\
\hline \multicolumn{5}{|c|}{ CUARTO CURSO } \\
\hline CÓDIGO & NOME & PERÍODO & TIPO & CRÉDITOS \\
\hline $650 G 01031$ & Análise de Estados Financeiros & $1^{0}$ cuadrimestre & Obrigatoria & 6 \\
\hline $650 G 01035$ & Aplicacións Informáticas para a Empresa & $1^{0}$ cuadrimestre & Optativa & 6 \\
\hline $650 G 01040$ & Economía e Xestión da Empresa Familiar & $1^{0}$ cuadrimestre & Optativa & 6 \\
\hline $650 G 01039$ & Finanzas Internacionais & $1^{0}$ cuadrimestre & Optativa & 6 \\
\hline $650 \mathrm{G} 01037$ & Fundamentos de Mercadotecnia & $1^{0}$ cuadrimestre & Optativa & 6 \\
\hline $650 G 01036$ & Inglés Empresarial Avanzado & $1^{0}$ cuadrimestre & Obrigatoria & 6 \\
\hline $650 G 01038$ & Mercado de Traballo na Perspectiva Histórica & $1^{0}$ cuadrimestre & Optativa & 6 \\
\hline $650 G 01042$ & Mercados e Intermediarios Financeiros & $1^{0}$ cuadrimestre & Optativa & 6 \\
\hline $650 G 01043$ & Traballo Fin de Grao & $2^{0}$ cuadrimestre & Obrigatoria & 12 \\
\hline $650 G 01041$ & Comercio Exterior & $2^{0}$ cuadrimestre & Optativa & 6 \\
\hline $650 G 01033$ & Introdución á Auditoría & $2^{0}$ cuadrimestre & Optativa & 6 \\
\hline $650 G 01044$ & Prácticas Externas & $2^{0}$ cuadrimestre & Optativa & 12 \\
\hline $650 G 01034$ & $\begin{array}{l}\text { Sistemas de Información para a Xestión } \\
\text { Financeira da Empresa }\end{array}$ & $2^{0}$ cuadrimestre & Optativa & 6 \\
\hline
\end{tabular}

Táboa 1.- Materias por cursos do Plan de Estudos do Grao en Ciencias Empresariais da UDC. Fonte: UDC (2013).

\section{2.- $O$ CAMBIO NO ROL DO DOCENTE: DO FOCUS ON TRANSFERING INFORMATION AO FOCUS ON LEARNING FACILITATION}

$\mathrm{Na}$ actualidade, existe un cambio nas concepcións didácticas do profesorado universitario (Zabalza, 2011). Así, prodúcense modificacións no rol docente do profesorado, que pasaría de ensinar transmitindo información (focus on transfering information) a ensinar xerando espazos de aprendizaxe (focus on learning facilitation). Se ben non se ten que entender que haxa que optar por unha ou outra concepción, si que é certo que o papel do profesorado é relevante dentro do "ambiente de aprendizaxe".

Prodúcese, por tanto, un cambio no "estilo de mediación" a adoptar polo docente. 0 obxectivo pretendido con este cambio é que os estudantes consigan unha aprendizaxe autónoma e profunda. Neste sentido, aínda que é frecuente pensar que un bo método de ensinanza implica 0 acompañamento e o seguimento intensivo do alumno por parte do profesorado (favorecido 
pola aplicación de Boloña), obsérvase que os estilos de mediación necesarios para chegar a unha aprendizaxe profunda non teñen por que ser intensivos nin directivos. De feito, Zabalza (2011) propón que precisamente o "estilo de mediación" debe mudar segundo o alumnado universitario vaia avanzando no desenvolvemento do título que estuda. Así, nos primeiros cursos, o profesorado debe manter unha actitude directiva e de certo seguimento e control sobre o traballo realizado polos estudantes; nos últimos cursos, é 0 alumno quen debe manter unha actitude activa, de participación e autocontrol sobre 0 seu proceso de aprendizaxe, coincidindo co desenvolvemento da súa propia capacidade para aprender de forma autónoma. É precisamente nos últimos cursos onde podemos situar a elaboración do TFG, cando xorden actores tan importantes como o profesorado no desenvolvemento da carreira do alumnado como poden ser os compañeiros, os libros e o propio alumno. Desta forma, o cambio no "estilo de mediación" debe condicionar tamén a metodoloxía empregada na aprendizaxe. Así 0 papel do docente dentro do proceso de elaboración do TFG enmárcase no eido da guía ou do acompañamento no desenvolvemento das habilidades xa traballadas durante a formación nos cursos iniciais (Restrepo, 2005).

\section{3.- 0 USO DE METODOLOXÍAS ACTIVAS NO PROCESO DE ELABORACIÓN DO TFG}

A proposta de desenvolvemento do proceso de guía para a elaboración do TFG por parte dos autores conduce a un cambio metodolóxico cara o uso de metodoloxías activas. Este cambio baséase no entendemento da aprendizaxe como un proceso construtivo que facilita o carácter autodirixido do propio TFG. Deste xeito estas metodoloxías activas dinamizan 0 uso de habilidades por parte do alumnado, o que vai permitir traballar en equipo, argumentar e reflexionar sobre 0 aprendido.

Este tipo de metodoloxías, por definición, implican unha maior preparación previa e un maior grado de control e supervisión do proceso de ensinanza-aprendizaxe de cada alumno, o que iría en liña cunha maior autonomía do estudante, maior aplicación práctica a traballar polo alumnado e unha maior implicación cara o traballo en equipo. 


\section{4.- APLICACIÓN DE ABPY Á ELABORACIÓN DO TFG}

Con esta proposta metodolóxica preténdese 0 desenvolvemento de habilidades que potencien a participación activa no proceso de aprendizaxe derivado da elaboración do TFG (Molina et al., 2007; Restrepo 2005). 0 problema dinamizador do TFG é propio do mundo real e da práctica profesional dun egresado do Grao en Empresariais: analizar o impacto que teñen, no custo para 0 cliente dunha entidade financeira, os cambios nas variables que afectan ao mesmo (gastos iniciais, xuros, duración da operación, tipo de operación, etc.). A análise deste elemento pódese incluír dentro da problemática e o contexto da transparencia das operacións e protección da clientela. Búscase así que 0 estudante se enfronte a unha problemática financeira de actualidade (produtos tóxicos, cláusulas chan, tipo fixo vs variable, etc.), recompile información, a analice, empregue a folla de cálculo como ferramenta metodolóxica xunto coa análise de escenarios, e extraia conclusións.

Proponse un achegamento teórico-práctico á problemática das operacións financeiras, para 0 que se consultará e revisará bibliografía. Analizaranse ademais as distintas variables e 0 seu impacto no custo (TIR) das operacións financeiras. Empregarase a folla de cálculo como ferramenta metodolóxica xunto coa análise de escenarios (Imaxe 1).

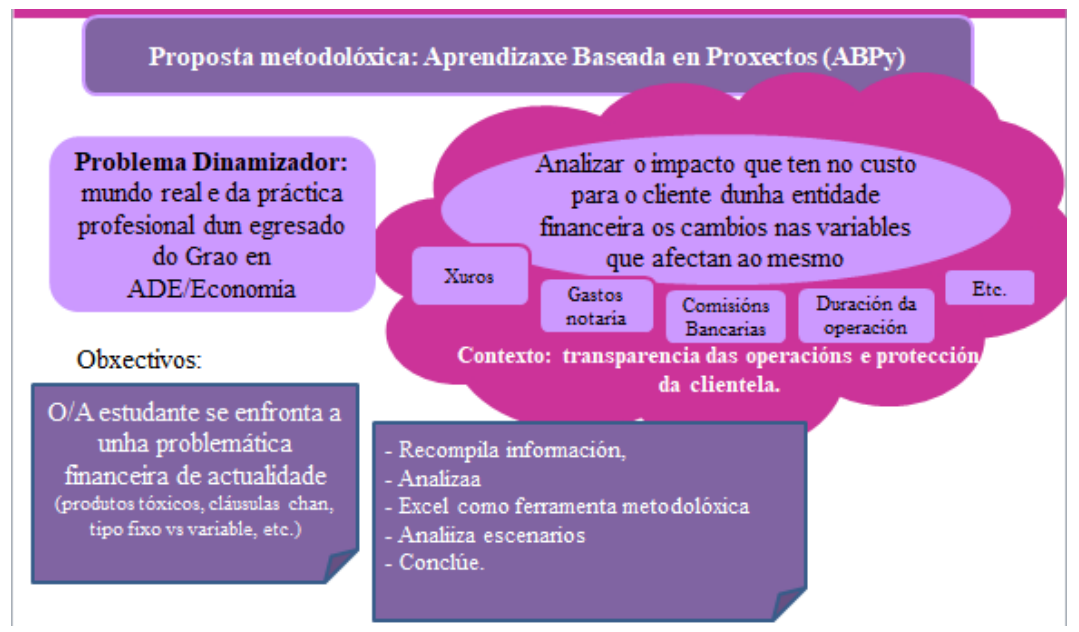

Imaxe 1. Resumo gráfico da proposta. Fonte: elaboración propia. 
As competencias a desenvolver no TFG polo alumno divídense en básicas ou xerais -tipo B-, transversais ou nucleares -tipo C- e específicas -tipo A- (UDC, 2013). Enúncianse a continuación (Táboa 2):

\section{TIPO A CÓDIGO COMPETENCIAS ESPECÍFICAS}

A1 CE1 - Aprender a aprender, por exemplo, como, cando, onde novos desenvolvementos persoais son necesarios.

A10 CE10 - Comprender e utilizar sistemas contables e financeiros.

A14 CE14 - Xestionar as operacións da empresa.

A15 CE15 - Xestionar os recursos financeiros.

A20 CE20 - Identificar e operar o software adecuado. Deseñar e implementar sistemas de información.

A21 CE21 - Identificar e utilizar as ferramentas adecuadas de matemáticas e estatística.

\section{TIPO B CÓDIGO COMPETENCIAS DO TÍTULO BÁSICAS / XERAIS}

B2 CB2 - Que os estudantes saiban aplicar os seus coñecementos ao seu traballo ou vocación dunha forma profesional e posúan as competencias que adoitan demostrarse por medio da elaboración e defensa de argumentos e a resolución de problemas dentro da súa área de estudo.

B3 CB3 - Que os estudantes teñan a capacidade de reunir e interpretar datos relevantes (normalmente dentro da súa área de estudo) para emitir xuízos que inclúan unha reflexión sobre temas relevantes de índole social, científica ou ética.

B4 CB4 - Que os estudantes poidan transmitir información, ideas, problemas e solucións a un público tanto especializado como non especializado.

B10 CG5 - Que os estudantes teñan unha perspectiva integral e destreza no manexo dos conceptos, técnicas e ferramentas empregados en cada unha das diferentes áreas funcionais, con especial referencia ás contables, financeiras e fiscais da empresa; así como entender as relacións que existen entre elas e cos obxectivos xerais da organización. Todo iso tendo en conta os principios de sustentabilidade e responsabilidade social das mesmas.

B13 CG8 - Que os estudantes identifiquen os requisitos legais da información financeira aos que a empresa debe enfrontarse.

\section{IIPOC CÓDIGO COMPETENCIAS DO TÍTULO TRANSVERSAIS / NUCLEARES}

C1 CT1 - Expresarse correctamente, tanto de forma oral coma escrita, nas linguas oficiais da comunidade autónoma.

C3 CT3 - Utilizar as ferramentas básicas das tecnoloxías da información e as comunicacións (TIC) necesarias para o exercicio da súa profesión e para a aprendizaxe ao longo da súa vida.

C4 CT4 - Desenvolverse para o exercicio dunha cidadanía aberta, culta, crítica, comprometida, democrática e solidaria, capaz de analizar a realidade, diagnosticar problemas, formular e implantar solucións baseadas no coñecemento e orientadas ao ben común.

C7 CT7 - Asumir como profesional e cidadán a importancia da aprendizaxe ao longo da vida.

Táboa 2.- Competencias a traballar durante o desenvolvemento do TFG "Análise de produtos bancarios dende unha perspectiva financeira. Fonte: UDC (2013). 
Optouse pola metodoloxía da aprendizaxe baseada en proxectos (ABPy) por canto radica na proposta da realización dun traballo complexo e completo, con forma de proxecto a desenvolver, elemento acaído para o que significa a elaboración dun TFG.

A metodoloxía obriga a propoñer os pasos a seguir: dividir o proxecto en pequenos elementos ou problemas, planificar o seu desenvolvemento, afondar na teoría, deseñar o modelo a aplicar para resolver o problema proposto, analizar a viabilidade de diversas alternativas que sirvan como solución, avaliación do aprendido, obtención de conclusións, etc.

Dentro do proceso de elaboración do TFG, realízanse sesións grupais de asistencia obrigatoria cun ritmo semanal ou quincenal para a explicación e seguimento do TFG. Compleméntase ademais o seguimento con atención individualizada cando sexa preciso a criterio dos docentes ou do alumnado individual.

0 esquema do TFG (Imaxe 2) baséase en traballar tres grandes elementos: afondar na lectura e comprensión das circulares 8/1990 e a 5/2012 do Banco de España (parte III), no repaso da teoría da análise das operacións financeiras (parte II) e no desenvolvemento do caso práctico baseado no traballo real sobre a virtual contratación de varias operacións financeiras, analizando a variación do custo real para 0 debedor ante posibles cambios nos parámetros contratados. 


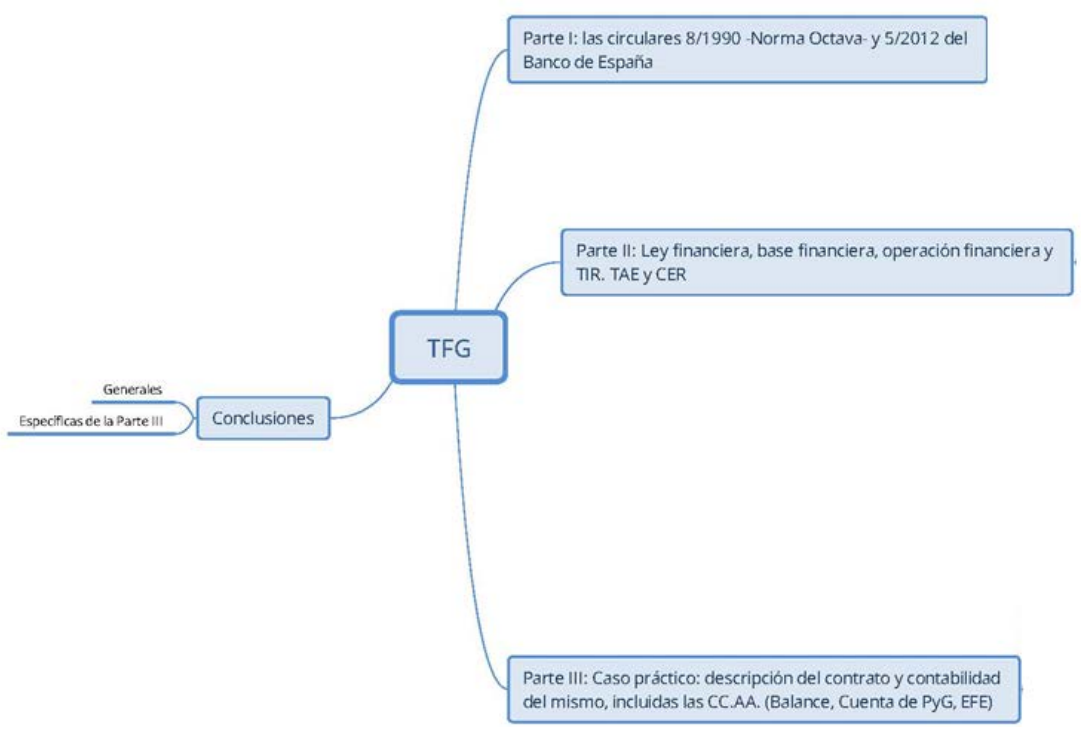

Imaxe 2. Esquema do TFG baseado en ABPy. Fonte: elaboración propia.

Tanto no inicio como no desenvolvemento, o alumnado visita distintas entidades financeiras como a unha directora dunha sucursal bancaria coa que poder contrastar información. A idea é que 0 alumnado teña un acceso de primeira man á operativa bancaria e poida coñecer o que significa 0 traballo cos produtos bancarios e financeiros, 0 que podería ser a súa práctica profesional no futuro.

Segundo o exposto, e a xuízo dos autores, dous son os elementos máis salientables da oferta deste TFG baseado en ABPy (Imaxe 3): a combinación de traballo persoal e en grupo e as actividades "experienciais", baseadas tanto nas visitas a entidades financeiras como nas entrevistas grupais cunha Directora de oficina bancaria para a recollida e contraste de información. 


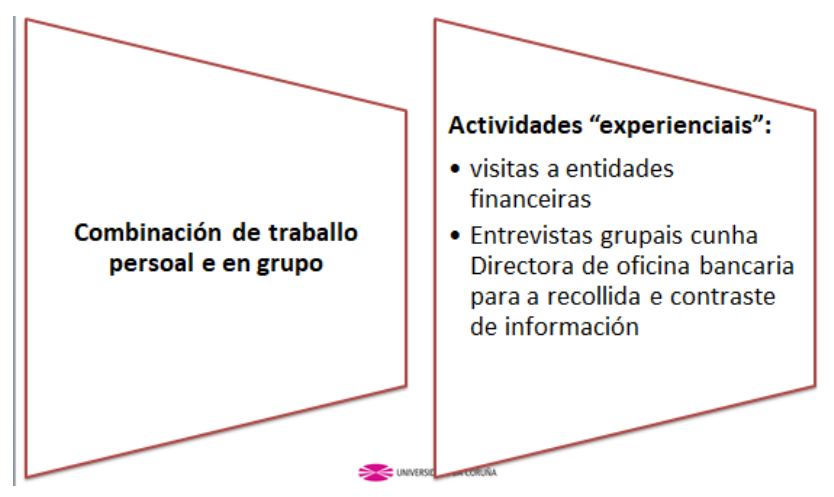

Imaxe 3. Elementos chave da proposta do TFG baseado en ABPy. Fonte: elaboración propia.

0 obxectivo último perseguido coa proposta metodolóxica radica en conseguir que a/o estudante pense, analice e actúe como profesional (Rekalde, 2011). A elaboración do TFG serve, pois, como adestramento holístico intensivo previo á incorporación á vida profesional. A través desta proposta de ensino-aprendizaxe activa, o estudante decatarase de que a resposta única non existe ante o problema económico-financeiro proposto. Mais dispón de ferramentas de análise, habilidades e coñecementos que lle permiten ofrecer solucións como profesional na materia en forma de proxecto, o TFG.

\section{RESULTADOS}

Os resultados acadados son moi satisfactorios tanto para o alumnado como para os docentes. Os docentes entenden que a metodoloxía é a acaída para este TFG, co que se ofrece unha entrada titorizada na práctica profesional financeira dos futuros egresados da Facultade de Economía e Empresa da UDC.

\section{CONCLUSIÓNS}

- Os autores propoñen 0 emprego da metodoloxía da "Aprendizaxe Baseada en Proxectos (ABPy)" como a máis acaída para desenvolver o TFG analizado. 
- A ABPy facilita o proceso de elaboración do TFG por canto radica na proposta da realización dun traballo complexo e completo, con forma de proxecto a desenvolver.

- 0 problema dinamizador do TFG é propio do mundo real e da práctica profesional dun egresado do Grao en Empresariais.

- 0 rol docente do profesorado dentro da elaboración do TFG pasa de ser informadores (focus on transfering information) a ser facilitadores de espazos de aprendizaxe (focus on learning facilitation).

- 0 titor do TFG debe funcionar como guía ou acompañante no desenvolvemento das habilidades xa traballadas durante os cursos iniciais.

- 0 obxectivo último perseguido coa proposta metodolóxica (ABPy) e coa temática do TFG radica en conseguir que a/o estudante pense, analice e actúe como profesional do eido das operacións financeiras.

- A elaboración do TFG significa para 0 alumnado un adestramento holístico intensivo previo á incorporación á vida profesional.

\section{REFERENCIAS}

Molina, J., García, A., Pedraz, A. \& Antón, V. (2007). Aprendizaje basado en problemas: una alternativa al método tradicional. Revista de la Red Estatal de Docencia Universitaria 3 (2), pp. 79-85.

Restrepo, B. (2005). Aprendizaje basado en problemas (ABP): una innovación didáctica para la enseñanza universitaria. Educación y educadores, 8, pp. 9-20.

Rekalde,I. (2011). ¿Cómo afrontar el trabajo fin de grado? Un problema 0 una oportunidad para culminar con el desarrollo de las competencias. Revista Complutense de Educación, 179, 22 (2), pp. 179-193. Doi: 10.5209/rev_RCED.2011.v22.n2.38488

Rullan, M., Fernández, M., Estapé, M. \& Márquez, D. (2011). La evaluación de competencias transversales en la materia Trabajo Fin de Grado. Revista de Docencia Universitaria, 8 (1), pp. $74-100$. 
Universidade da Coruña -UDC-. (2013). Memoria do Plan de Estudos do Grao de Ciencias Empresariais, aprobada 0 03/11/2008 e modificada 0 24/07/2013. Recuperado de: http://www.economicas.udc.es/subido/MEMORIA_GEMP_V2013.pdf.

Zabalza, M.A. (2011). Metodología docente. Revista de Docencia Universitaria, 9 (3), pp. 7598. Recuperado de: http://red-u.net/redu/files/journals/1/articles/302/public/302-627-1PB.pdf. 